\title{
"Synthesis of Liquid Crystals with Substituents in Terminal Benzene cores and their Mesomorphic Behaviour"
}

\author{
Vinay.S.Sharma ${ }^{1}$ and R.B. Patel ${ }^{\star}$ \\ Chemistry Department, K.K. Shah Jarodwala Maninagar Science College, Gujarat University, \\ Ahmedabad, Gujarat, India \\ E mail address: vinaysharma3836@gmail.com, roshanpatel770@gmail.com
}

Keywords: Nematic, Smectic, Liquid Crystal, Mesophase.

\begin{abstract}
A new homologous series consisting of thirteen homologues central ester and chalcone linkage with Pentyloxy side chain at terminal benzene ring is synthesized and their mesomorphic properties are studied, with the exception of the methyl, ethyl and propyl homologues. However, the rest of homologues show mesomorphism enantiotropically manner with exhibition of nematic phase. The texture image of the nematic mesophases is observed by optical polarizing microscope equipped with heating stage (POM) is threaded or Schlieren type. An odd-even effect is observed in the nematic-isotropic curve with alternation in transition temperatures. The mesomorphic properties of the novel series are compared with other structurally similar homologous series. Analytical and spectral data confirm the molecular structure of the compounds.
\end{abstract}

\section{INTRODUCTION}

Some substances exhibits an intermediate state of matter with a molecular ordering in between that of the conventional crystalline solid and isotropic liquid phases, and this state of matter is called a liquid crystal (LC) state or mesomorphic state [1,2]. Chalconyl derivatives are well-known for their biological activity as antibacterial, antifungal, antimalarial and anticancer $[3,4]$. Here, in this article, we present the novel chalconyl derivatives that consists of the three phenyl rings bonded through $-\mathrm{CH}=\mathrm{CH}-\mathrm{COO}$ - and $-\mathrm{CO}-\mathrm{CH}=\mathrm{CH}$ - central bridges to the molecular rigidity and flexible end groups $(-\mathrm{OR})$ and terminal side chain $\left(-\mathrm{OC}_{5} \mathrm{H}_{11}\right)$ at end side of benzene core. In the present investigation, we study the molecular rigidity and flexibility combine to facilitate suitable magnitudes of intermolecular forces of attraction required to induce an LC phase $[5,6,7,8,9]$. The novel synthesized substances will be characterized and then reported with evaluation of thermotropic data and will be interpreted and compared with structurally similar series on the basis of molecular rigidity and flexibility. Numbers of homologues series have been reported in literature till the date $[10,11,12,13,14,15,16,17,18,19,20]$. Group efficiency order and structure relation with mesomorphism will be derived.

\section{EXPERIMENTAL}

\section{Synthesis}

4-hydroxy cinnamic acid (A) was synthesized by the reaction between P-hydroxy benzaldehyde and Malonic acid in pyridine in presence of few drops of piperidine as a catalyst [21], 4-n-alkoxy of cinnamic acid (B) were synthesized by a modified method reported by Dave and Vora etal [22 ]. $\alpha$ 4-Hydroxy benzoyl $\beta$-4 -petyloxy phenyl ethylene (C) was prepared by usual established method. Final product (D) was prepared by the esterification of (B) and (C) [23]. Alkyl halides, EtOH, $\mathrm{KOH}$, Acetone, 4-Hydroxy acetophenone, 4-Hydroxy benzaldehyde, Pentyl Bromide, Malonic acid etc., required for synthesis were used as received except solvents which were dried and remove by rota evaporator. The synthetic route to the series is mentioned below as scheme-1 


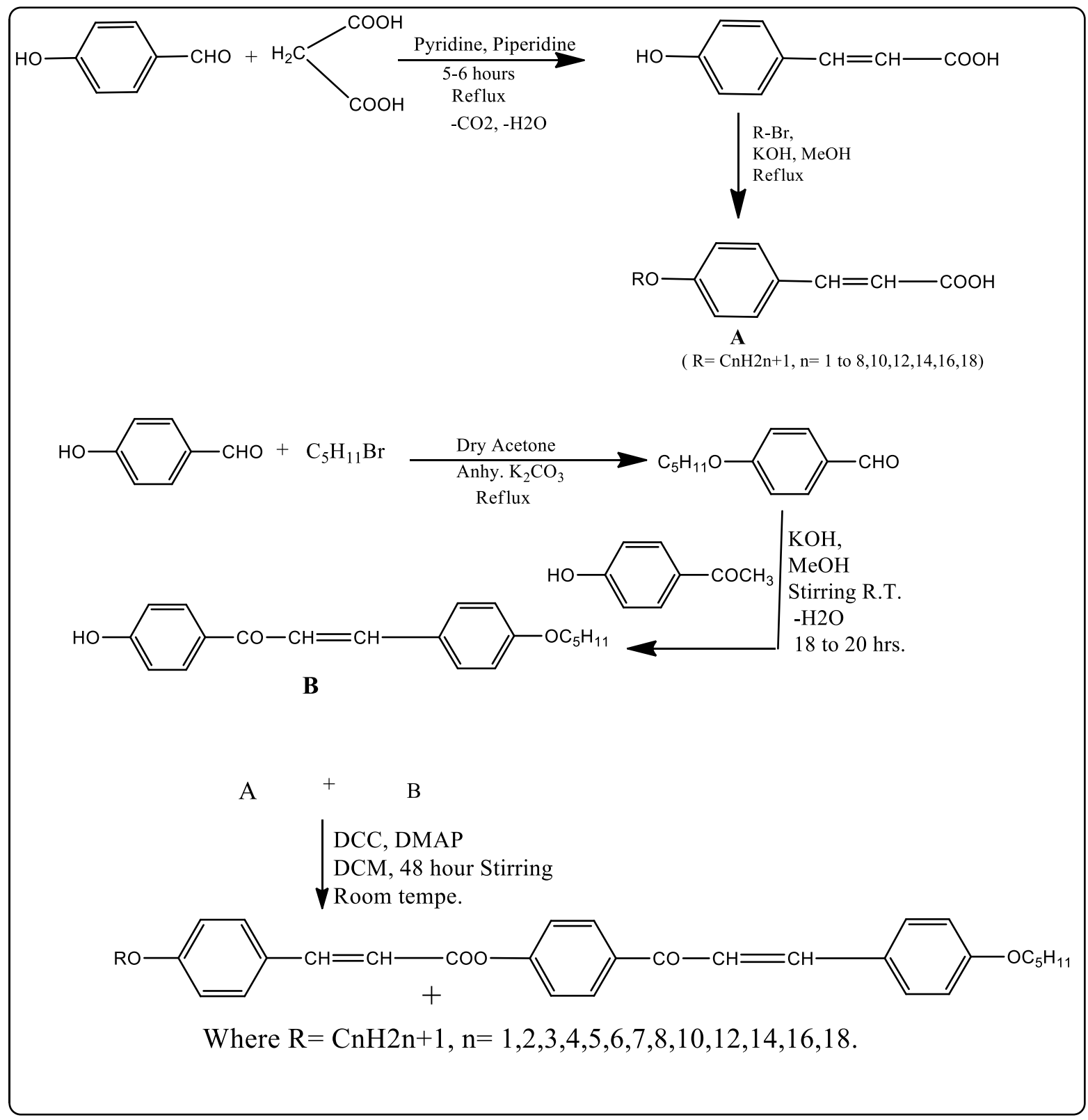

Scheme 1:- Synthetic route to the series

\section{CHARACTERIZATION}

Selected members of the novel homologous series were characterized by Elemental Analysis, infra-red spectroscopy, ${ }^{1} \mathrm{H}$ NMR spectra. IR spectra were recorded by Perkin-Elmer spectrum GX, ${ }^{1} \mathrm{H}$ NMR spectra were recorded on Bruker using $\mathrm{CDCl}_{3}$ as solvent. Microanalysis was performed on a Perkin-Elmer PE2400 CHN analyzer. Transition temperature and LC properties (Textures) were determined using an optical polarizing microscopy equipped with a heating stage. Textures of nematic phase determined by miscibility method. 


\section{ANALYTICAL DATA}

Table 1:- Elemental Analysis for (1) Butoxy, (2) Decyloxy, (3) Dodecyloxy (4) Octadecyloxy derivatives

\begin{tabular}{|c|c|c|c|c|c|}
\hline \multirow{2}{*}{ Sr. No. } & \multirow{2}{*}{ Molecular formula } & \multicolumn{2}{|c|}{$\%$ Elements found } & \multicolumn{2}{c|}{ \%Elements Theoretical } \\
\cline { 3 - 5 } & & $\mathrm{C}$ & $\mathrm{H}$ & $\mathrm{C}$ & $\mathrm{H}$ \\
\hline 1 & $\mathrm{C}_{33} \mathrm{H}_{36} \mathrm{O}_{5}$ & 77.30 & 6.99 & 77.34 & 7.03 \\
\hline 2 & $\mathrm{C}_{39} \mathrm{H}_{48} \mathrm{O}_{5}$ & 78.47 & 8.01 & 78.52 & 8.05 \\
\hline 3 & $\mathrm{C}_{41} \mathrm{H}_{52} \mathrm{O}_{5}$ & 78.81 & 8.29 & 78.84 & 8.33 \\
\hline 4 & $\mathrm{C}_{47} \mathrm{H}_{63} \mathrm{O}_{5}$ & 79.73 & 8.89 & 79.77 & 8.91 \\
\hline
\end{tabular}

IR Spectra in $\mathrm{cm}^{-1}$ for Hexyloxy \& Decyloxy Derivatives:

Octyloxy : 663( $\mathrm{Cis}-\mathrm{CH}=\mathrm{CH}-), 710$ Polymethylene $\left(-\mathrm{CH}_{2}-\right)$ n of $-\mathrm{OC}_{5} \mathrm{H}_{11}, 831(-\mathrm{C}-\mathrm{H}-\mathrm{def}$. $\mathrm{m}$ disubstituted-Para), 711 Polymethylene $\left(-\mathrm{CH}_{2}-\right)$ of $-\mathrm{OC}_{6} \mathrm{H}_{13}, 937$ (-C-H- def. hydrocarbon), 1168 , 1251 and 1390 ( $-\mathrm{C}-\mathrm{O}$ str in $-\left(\mathrm{CH}_{2}\right)$ n chain), 1446 and $1467 \quad\left(-\mathrm{C}-\mathrm{H}-\right.$ def. in $\left.\mathrm{CH}_{2}\right), 1510 \quad(-\mathrm{C}=\mathrm{C}-$ )str, 1602 and 1728 (-C=O group) and (-COO- ester group), 2848 and $2916\left(-\mathrm{C}-\mathrm{H}\right.$ str in $\left.\mathrm{CH}_{3}\right)$.

Decyloxy : 663( $\mathrm{Cis}-\mathrm{CH}=\mathrm{CH}-), 711$ Polymethylene $\left(-\mathrm{CH}_{2}-\right)$ n of $-\mathrm{OC}_{5} \mathrm{H}_{11}, 831$ ( $-\mathrm{C}-\mathrm{H}-\mathrm{def}$. m disubstituted-Para), 731 Polymethylene $\left(-\mathrm{CH}_{2}-\right)$ of $-\mathrm{OC}_{10} \mathrm{H}_{21}, 937$ (-C-H- def. hydrocarbon), 1062 (C-O-) Str, 1390, 1165 and 1253 ( $-\mathrm{C}-\mathrm{O}$ str in $-\left(\mathrm{CH}_{2}\right)$ n chain, 1452(-C-H- def. in $\left.\mathrm{CH}_{2}\right), 1502$ ( $\mathrm{C}=\mathrm{C}-)$ str, 1600 and 1671 (-C=O group) and (-COO- ester group), 2848 and 2918 (-C-H str in $\left.\mathrm{CH}_{3}\right)$.

\section{${ }^{1} \mathrm{HNMR}$ spectra in $\mathrm{CDCl}_{3}$ in $\boldsymbol{\delta} \mathbf{p p m}$ for Hexyloxy \& Dodecyloxy Derivative:}

Hexyloxy : $0.87\left(\mathrm{t},-\mathrm{CH}_{3}\right.$ of $\left.-\mathrm{C}_{5} \mathrm{H}_{11}\right), 1.2-1.4\left(\mathrm{~m}\right.$, n-poly methylene groups of $\left.-\mathrm{OC}_{5} \mathrm{H}_{11}\right), 1.78(\mathrm{~m}, \mathrm{n}-$ poly methylene groups of $\left.-\mathrm{OC}_{6} \mathrm{H}_{13}\right), 3.5-3.7\left(\mathrm{~s},-\mathrm{OCH}_{2}-\mathrm{CH}_{2}\right.$-of $\left.-\mathrm{OC}_{6} \mathrm{H}_{13}\right), 4.01\left(\mathrm{~s},-\mathrm{OCH}_{2}-\mathrm{CH}_{2}\right.$-of $\left.\mathrm{OC}_{6} \mathrm{H}_{13}\right) 6.51(\mathrm{~d},-\mathrm{CH}=\mathrm{CH}-)$ 6.9-7.4(s,-CO-CH=CH), 8.09 (s, p-disubstituted phenyl ring).

Dodecyloxy : $0.87\left(\mathrm{t},-\mathrm{CH}_{3}\right.$ of $\left.-\mathrm{C}_{5} \mathrm{H}_{11}\right), 1.2-1.5\left(\mathrm{~m}, \mathrm{n}\right.$-poly methylene groups of-OC $\left.\mathrm{OC}_{5} \mathrm{H}_{11}\right), 1.80(\mathrm{~m}, \mathrm{n}-$ poly methylene groups of $\left.-\mathrm{OC}_{12} \mathrm{H}_{25}\right), 3.5-3.6\left(\mathrm{~s},-\mathrm{OCH}_{2}-\mathrm{CH}_{2}-\mathrm{of}-\mathrm{OC}_{12} \mathrm{H}_{25}\right), 4.0\left(\mathrm{~s},-\mathrm{OCH}_{2}-\mathrm{CH}_{2}\right.$-of $\left.\mathrm{OC}_{12} \mathrm{H}_{25}\right), 6.47(\mathrm{~d},-\mathrm{CH}=\mathrm{CH}-)$ 6.9-7.5(s,-CO-CH=CH),8.1 (s, p-disubstituted phenyl ring).

Table 2:-Texture of Nematic Phase of $\mathrm{C}_{7}, \mathrm{C}_{10}, \mathrm{C}_{14}, \mathrm{C}_{16}$ by miscibility method.

\begin{tabular}{|c|c|c|}
\hline Sr. No. & Homologue & Texture \\
\hline 1 & $\mathrm{C}_{7}$ & Threaded \\
\hline 2 & $\mathrm{C}_{10}$ & Threaded \\
\hline 3 & $\mathrm{C}_{14}$ & Schlieren \\
\hline 4 & $\mathrm{C}_{16}$ & Schlieren \\
\hline
\end{tabular}

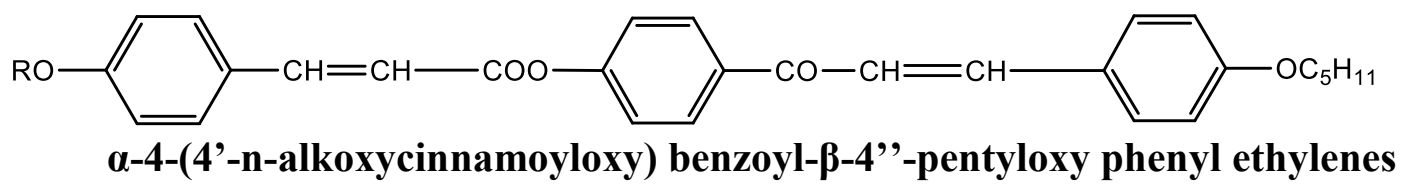


Table 3 :- Transition Temperature of Homologous series

\begin{tabular}{|c|c|c|c|c|}
\hline \multirow{2}{*}{ Sr.no } & R=n-alkyl group & \multicolumn{3}{|c|}{ Transition temperatures in ${ }^{0} \mathrm{C}$} \\
\cline { 3 - 5 } & & Smectic & Nematic & Isotropic \\
\hline 1 & $\mathrm{C} 1$ & - & - & 136 \\
\hline 2 & $\mathrm{C} 2$ & - & - & 132 \\
\hline 3 & $\mathrm{C} 3$ & - & - & 118 \\
\hline 4 & $\mathrm{C} 4$ & - & 92 & 116 \\
\hline 5 & $\mathrm{C} 5$ & - & 85 & 112 \\
\hline 6 & $\mathrm{C} 6$ & - & 76 & 104 \\
\hline 7 & $\mathrm{C} 7$ & - & 74 & 101 \\
\hline 8 & $\mathrm{C} 8$ & - & 84 & 108 \\
\hline 9 & $\mathrm{C} 10$ & - & 88 & 116 \\
\hline 10 & $\mathrm{C} 12$ & - & 82 & 118 \\
\hline 11 & $\mathrm{C} 14$ & - & 78 & 98 \\
\hline 12 & $\mathrm{C} 16$ & - & 60 & 96 \\
\hline 13 & $\mathrm{C} 18$ & & & 74 \\
\hline
\end{tabular}

\section{Homologues series}

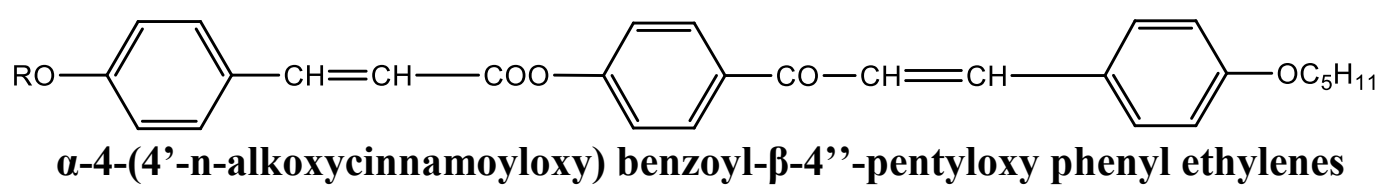

Figure 1 :- Phase diagram of Series 


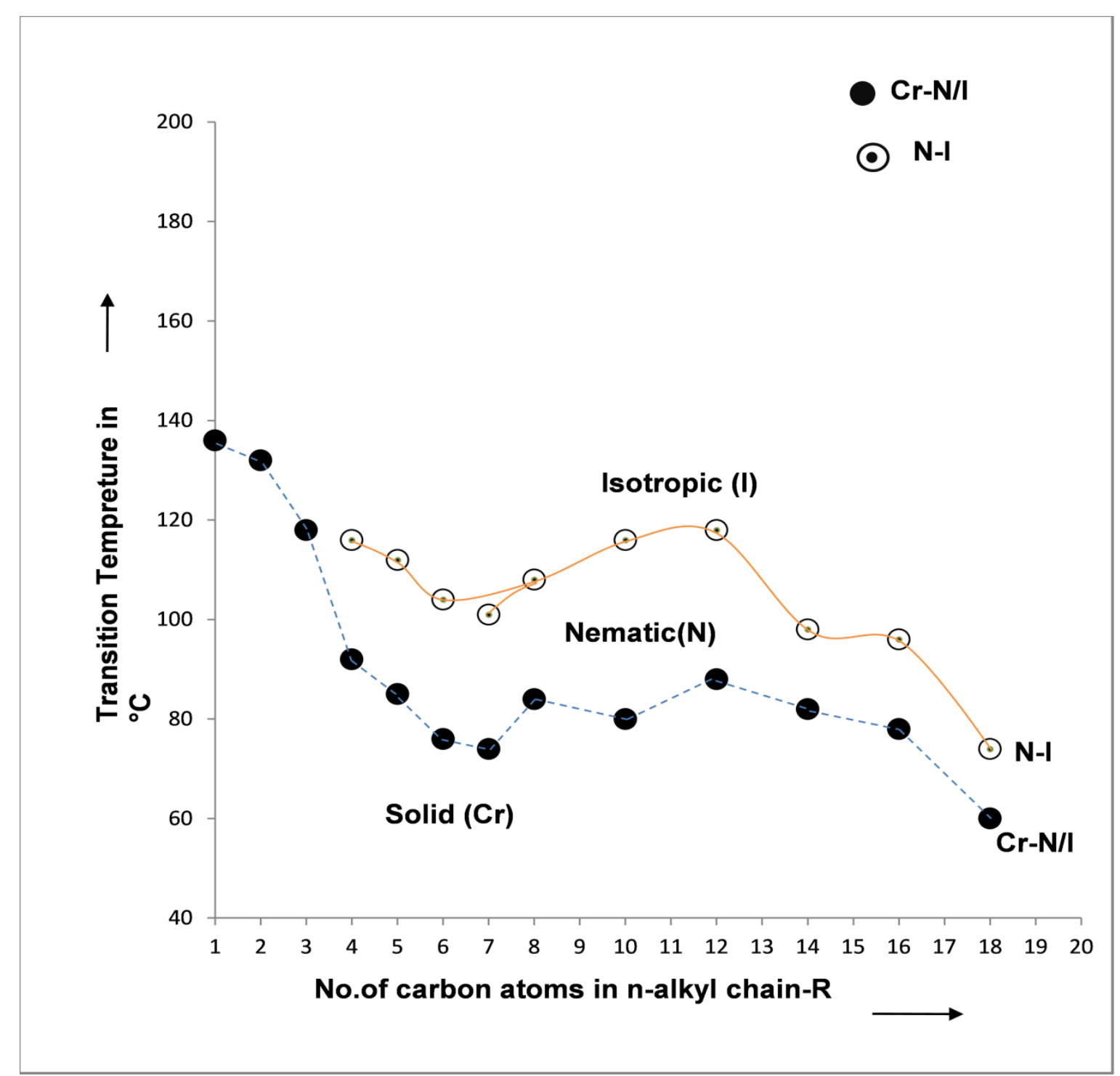

\section{RESULT AND DISCUSSION}

4-hydroxy derivative of chalcone ( m.p. $116^{\circ} \mathrm{C}$, yield $74 \%$ ) is a linear shape nonmesomorphic compound but linking with cis cinnamic acid its possesses mesophase. Mesomorphic character commences at $\mathrm{C}_{4}$ homologue and continued up to last $\mathrm{C}_{18}$ homologue as enantiotropically manner and shows nematic phase without exhibition of smectogenic phase. $\mathrm{C}_{1}$ to $\mathrm{C}_{3}$ homologues are nonmesomorphic due to their high crystallising tendency to directly converted in to liquid without showing any kind of mesophase. Transition temperatures (Table-3) as determined by POM were plotted against the number of carbon atoms present in n-alkyl chain of the left n-alkoxy terminal end group (-OR). The mesogenic properties are varied for homologue to homologue only for changing to addition of methylene group at the terminal side chain, while the central linkage core remains same in present homologues series.

In this present article, we show the liquid crystalline property of chalconyl ester from $\mathrm{C}_{4}$ to $\mathrm{C}_{18}$ homologues series. A phase diagram (Figure-1) is obtained to show $\mathrm{Cr}-\mathrm{I} / \mathrm{N}$ and $\mathrm{N}-\mathrm{I}$ transition curves. It is shown that N-I transition curve exhibited odd-even effect. Transition curve of odd and even homologue members of a present newly homologues series merged at $\mathrm{C}_{8}$ homologue and it possesses higher transition temperature. It is observed that all the homologues have same tail group $\left(-\mathrm{OC}_{5} \mathrm{H}_{11}\right)$, in which the Pentyl chain is bonded through the oxygen atoms, the $\mathrm{Cr}-\mathrm{I} / \mathrm{N}$ and N-I curves shows zigzag path of rising and falling tendency as series is ascended with overall falling tendency and behaved in normal manner. The N-I transition curve for even members occupied higher position as compared to odd members, odd and even membered transition curves is initially 
decrease than increase up to $\mathrm{C}_{12}$ homologue with respect to $\mathrm{C}_{7}$ and $\mathrm{C}_{9}$ homologues, after $\mathrm{C}_{12}$ homologue, the curves descends to $\mathrm{C}_{14}, \mathrm{C}_{16}$ and $\mathrm{C}_{18}$ homologue. Thus, it behaved in normal manner with negligible abnormality at $\mathrm{C}_{5}$ is attributed due to zero difference of group polarities of $-\mathrm{OC}_{5} \mathrm{H}_{11}$ at left and right end groups similarity, Hence the magnitude and vector sums of polarities of all the present bonds of $-\mathrm{OC}_{5} \mathrm{H}_{11}$ are exactly equal and contrasting in directions which results into actual efficiency in the magnitudes of molecular flexibility replicating to mesogenic behaviour of $\mathrm{C}_{4}$, moderately than the rest of the homologues of a present novel series . from the Analytical and spectral data, we confirms that the molecular structures of homologues. Textures of nematic phase are threaded or schlieren as determined by miscibility method and directly observed through microscopic observation or texture image by POM.

The exhibition of nematogenic mesophase formation by $\mathrm{C}_{4}$ homologue to $\mathrm{C}_{18}$ homologues is recognized to the suitable magnitudes of end to end intermolecular anisotropy forces of attractions and propinquity as a consequence of appreciative molecular rigidity and flexibility prompted from permanent dipolemoment across the long molecular axis, appropriate magnitudes of dispersion forces and dipole-dipole interactions, molecular polarity and polarizability, which enhance the molecules under microscopy (POM) study to drift on the surface with statically parallel orientational order inside definite range of temperature as nematic phase. However, none of the homologue molecules shows sliding layered molecular organisation under floating condition due to insufficient and short intermolecular cohesive forces and closeness to accumulation layered molecular arrangement in preoccupied crystal lattices in rigid crystalline state prior to exposure of thermal vibrations. Thus, smectogenic mesophase formation is disappeared throughout the series of present investigation.

Thermal stability for nematic is 104.3 and mesomorphic path length ranges form $14^{0} \mathrm{C}$ to $36^{0} \mathrm{C}$ at the $\mathrm{C}_{18}$ to $\mathrm{C}_{10}$ homologue respectively. Thus, thermometric properties changing from homologue to homologue in present series with changed in litheness part at terminal side chain, due to number of methylene unit or units of left n-alkoxy terminally positioned end group, keeping rest of the molecular part unaffected throughout the series. Thus, series of current examination is partly nematogenic and low melting type and relatively short ranged liquid crystallity in addition to low thermal stability. The failure to show liquid crystalline phase in $C_{1}$ to $C_{3}$ homologues are unable to resist the exposed thermal vibrations due to unsuitable magnitudes of intermolecular end to end or/and lateral attractions which shortly breaks crystal lattices and smoothly transform crystalline state to isotropic state without passing through LC state, due to low dispersion forces and low magnitudes of dipole-dipole and electronic interactions between instant dipole produced by spontaneous alternations of electron clouds of the molecule prominent to high crystallising tendency. Thus, molecules of nonmesomorphs arbitrarily oriented in all possible directions with high order of disorder or uncontrolled movement. Such molecules do not attain monotropic LC state on cooling the isotropic phase. Thus, exhibition of mesomorphism either smectic or nematic is absent for $\mathrm{C}_{1}$ to $\mathrm{C}_{3}$ homologues.

The changing trends in mesomorphic properties like thermal stability, commencement of mesophase, mesophaselength etc. depended upon molecular length and linearity of molecule which consecutively undergo varied and dew to that changing permanent dipole moment across the long molecular axis, dispersion forces, thermodynamic quantity enthalpy $(\Delta H)$, prolonged the noncoplanarity which related to changing the molecular structure with linearity, rigidity and flexibility of molecules. The molecular rigidity due to phenyl rings and central bridges linking core with ( $-\mathrm{CH}=\mathrm{CH}-\mathrm{COO}-)$ and ( $-\mathrm{CO}-\mathrm{CH}=\mathrm{CH}-)$ to all homologue in the same series, but the molecular flexibility due to difference in polarity of two end groups of present series undergo changed. Therefore, the magnitudes of their combined effect due to flexibility and rigidity, which changes from homologue to homologue in the same series. Thus, thermotropic resistivity and suitable magnitudes of intermolecular cohesion energy and consequently mesomorphic tendency of a molecule show vibration in mesomorphic properties of a present novel series are compared with the structurally similar other known homologous series as shown below in figure- 2 . 


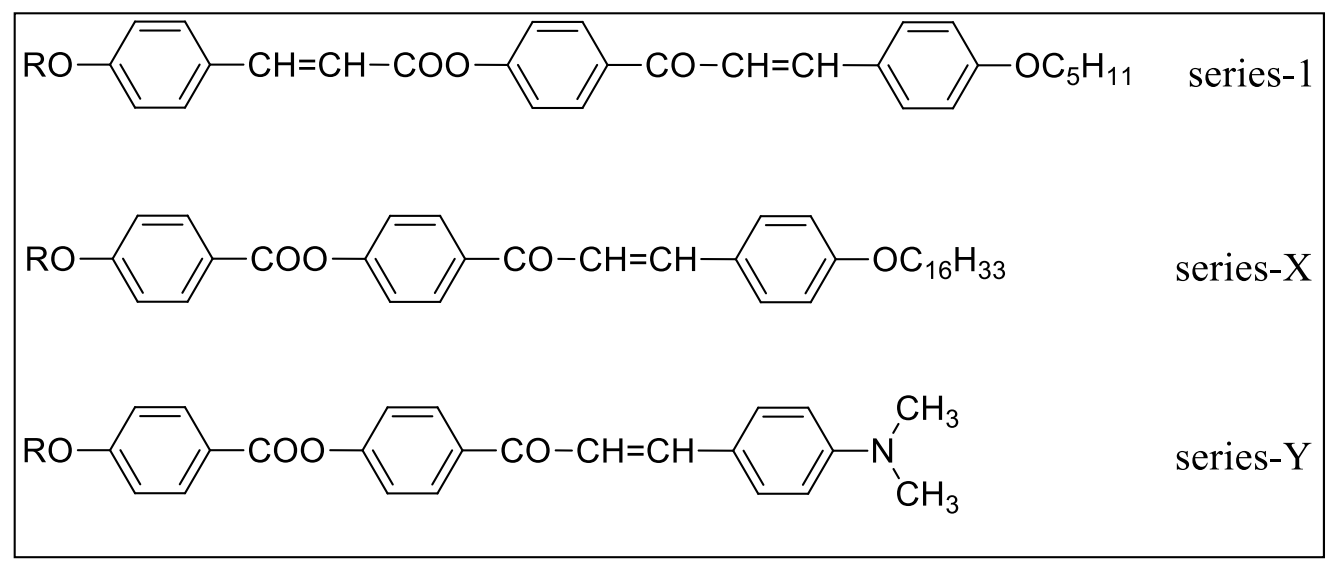

Figure:2 Structurally similar series

Homologous series 1 and $\mathrm{X}$ are identical with respect to three phenyl rings, central bridge linking middle and third phenyl ring left and left terminal end groups for the same homologue from series- 1 to series-X. But they differ with respect to central bridges $-\mathrm{CH}=\mathrm{CH}-\mathrm{COO}-$ and $-\mathrm{COO}-$ linking first and central phenyl rings for the similar homologue from series-1 to series-X and $\mathrm{Y}$. Thus, combine effect of molecular rigidity plus flexibility diverge for the same homologue from series to series and from homologue to homologue in the same series. Series Y attributed smectic as well as nematic mesophase due to the broadening or spreading of molecule which, reduces end to end attractions and increases polarizability favours to sliding layered molecular arrangement of smectic phase than stastically parallel orientational order of molecules in floating condition between Sm-N and N-I transition temperatures. Homologous series 1 and $\mathrm{X}$ are identical in all respect except right handed tail end groups, $-\mathrm{OC}_{16} \mathrm{H}_{33}$ and $-\mathrm{NH}\left(\mathrm{CH}_{3}\right)_{2}$ for the same homologue from series 1 to series $\mathrm{Y}$ and from homologue to homologue in the same series as a consequence of combined effect of molecular rigidity plus flexibility whose magnitudes decides the possibility of inducing mesomorphism and its thermotropic behaviours. Following table-3 represents some thermometric behaviours of presently investigated novel chalconyl homologous series-1 and the series-X [24] and Y [25] chosen for comparative study.

Table-3 Relative Thermal Stability in ${ }^{0} \mathrm{C}$

\begin{tabular}{|c|c|c|c|}
\hline Series & 1 & $\mathbf{X}$ & $\mathbf{Y}$ \\
\hline $\begin{array}{l}\text { smectic-isotropic } \\
\text { or } \\
\text { smectic-nematic } \\
\text { Commencement of } \\
\text { Smectic phase }\end{array}$ & - & - & $\begin{array}{c}59.6 \\
\left(\mathrm{C}_{7}-\mathrm{C}_{18}\right) \\
\mathrm{C}_{7}\end{array}$ \\
\hline $\begin{array}{l}\text { Nematic-Isotropic } \\
\text { Commencement of } \\
\text { Nematic phase }\end{array}$ & $\begin{array}{c}104.3 \\
\left(\mathrm{C}_{4}-\mathrm{C}_{18}\right) \\
\mathrm{C}_{4}\end{array}$ & $\begin{array}{c}113.14 \\
\left(\mathrm{C}_{6}-\mathrm{C}_{18}\right) \\
\mathrm{C}_{6}\end{array}$ & $\begin{array}{c}76.6 \\
\left(\mathrm{C}_{4}-\mathrm{C}_{18}\right) \\
\mathrm{C}_{4}\end{array}$ \\
\hline $\begin{array}{c}\text { Total upper and } \\
\text { lower mesophase } \\
\text { length range in }{ }^{0} \mathrm{C} \\
\mathrm{C}_{\mathrm{i}} \text { to } \mathrm{C}_{\mathrm{j}}\end{array}$ & $\begin{array}{lll}14.0 & \text { to } 36.0 \\
\mathrm{C}_{18} & \mathrm{C}_{10}\end{array}$ & $\begin{array}{lll}10.0 & \text { to } 26.0 \\
\mathrm{C}_{8} & & \mathrm{C}_{10}\end{array}$ & $\begin{array}{lll}6.0 & \text { to } & 35.0 \\
\mathrm{C}_{5} & & \mathrm{C}_{16}\end{array}$ \\
\hline
\end{tabular}

Careful observation at above table- 3 indicates that,

- Presently investigated series-1 and a structurally similar series-X are nematogenic, whereas, series $\mathrm{Y}$ is smectogenic and nematogenic character.

- The nematic property originates from $\mathrm{C}_{4}$ (Series-1 and Series-Y), $\mathrm{C}_{6}$ (Series-X) homologue. 
- Nematic thermal stability of present novel series-1 is the lowest as compare to Series $-\mathrm{X}$ under comparison, though it is lowest as compare to Series-Y.

- Thermal stability is enriched if $-\mathrm{CH}=\mathrm{CH}-\mathrm{COO}$ - central bridge is replaced by -COO- in Series X. However, in series Y it becomes lower due to the effect of terminal end group.

- Odd-even effect is exhibited by the transition curve or curves of respective series.

In series 1 and series $\mathrm{X}$, intermolecular suitable magnitudes of anisotropic end to end forces as a consequence of molecular rigidity and flexibility, due to the appropriate permanent dipole moment, dipole- dipole interactions etc. are adequate and fittest to facilitate and to stimulate nematogenic character, but insufficient to retain focal conic networking molecular arrangement in rigid crystal and preceding sliding layered molecular arrangement in floating condition under showing thermal vibrations. Thus, smectogenic character fails to facilitate in all the series-1, X, while present in series- Y under comparative study. The extent of molecular noncoplanarity for all the series $1, \mathrm{X}$ and $\mathrm{Y}$ are equivalent but it slightly differs for the difference of $-\mathrm{CH}=\mathrm{CH}$ - unit in case of series-1 which, causes a little bit early $\left(\mathrm{C}_{4}\right)$ commencement from $\left(\mathrm{C}_{6}\right)$ homologue for series 1 and $\mathrm{X}$. The observed difference for thermal stabilities is attributed to the unusual and unexpected molecular status of n-alkyl chain of both ended n-alkoxy terminals $-\mathrm{OR}$ and $-\mathrm{OC}_{5} \mathrm{H}_{11}$ depending upon resultant contrary polarity difference of $-\mathrm{OR}$ and $-\mathrm{OC}_{5} \mathrm{H}_{11}$, which tempts the thermal resistivity, degree of mesomorphism and transition temperatures of homologues. Hence, thermal stabilities and upper and lower mesophase-lengths ranges of series1, $\mathrm{X}$ and $\mathrm{Y}$ are not much differed in magnitudes.

\section{CONCLUSIONS}

In this article, we demonstrated a newly chalconyl ester series is partly nematogenic whose degree of mesomorphism is shorter and of low melting type without exhibition of smectogenic property. The group efficiency order derived on the basis of (i) thermal stability (ii) early beginning of mesophase (iii) higher degree mesomorphism are as under.

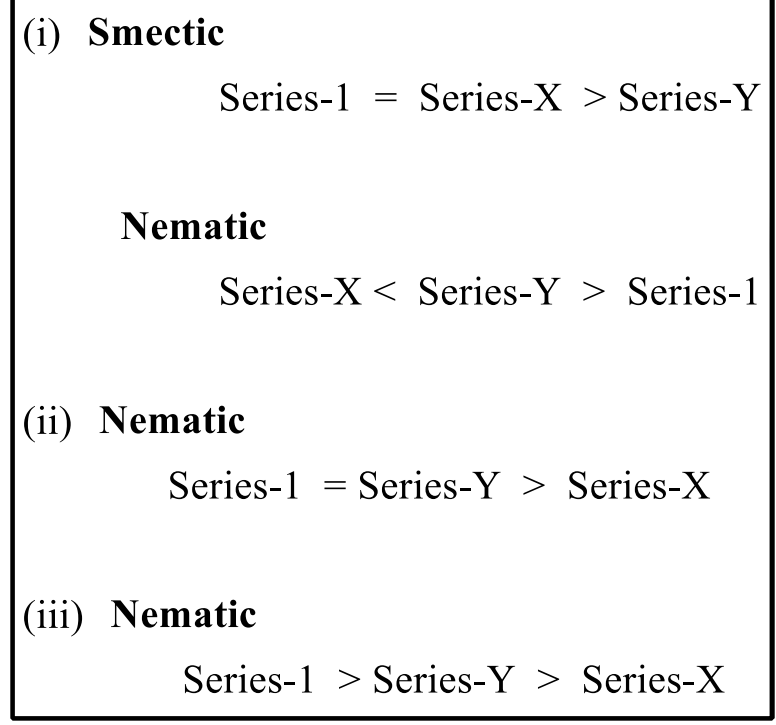

- Homologous series with longer n-alkyl chains bonded to third phenyl ring through oxygen atoms as tail end group are nematogenic only of low degree of mesomorphism.

- Difference of group polarities at the two terminal end groups decides the mesogenic behaviours of individual homologue and the same homologous series as a whole.

- Mesogenic homologues are useful for the study of binary systems for the manufacture of LC devices to be operated between $45^{\circ} \mathrm{C}$ to $50^{\circ} \mathrm{C}$.

- Chalconyl derivatives are bioactive molecules, which can be further studied for their bioactivity for the pharmaceutical and medicinal formulation. 


\section{Acknowledgement}

Authors are acknowledge thanks to Dr. R. R. Shah, principal of K. K. Shah Jarodwala Maninagar Science College, Ahmedabad. Authors are thanks to Dr. A.V. Doshi, Ex-principal of M.V.M. Science College - Rajkot for his constant support, inspirations and help, as and when needed during the course of present investigation. Authors thank to NFDD Centre for the analytical services and spectral services.

\section{References}

[1] G.W. Gray and P.A. Winster (Eds) Liquid Crystal and plastic crystals, chapter-6.2, The role of liquid crystal in life processes by G.T. Stewart, Vol-1,PP.308-326.

[2] Hird. M, Toyne. K. J, and Gray G.W., Day S.E and Mc. Donell D.G (1993) , Liq. Cryst. 15, PP.123.

[3] W.S.Kim, S.J. Elston, and F.P. Raynes, Display29 (2008) PP.458-463.

[4] Upendra K Jain, Rich K Bhatia, Akkinepally R. Rao, Ranjit singh, Saxsena Ajit K and Seha lrun " Design and Development of Halogenated Chalcone derivatives as potential anticancer Agents " Tropical Journal of pharmaceutical Research, January 2014: 13(1), 73-80.

[5] ImranTadwee,Dr.Sahanashahi,vivekRamteke,Iftequarsyed, Liquid crystal pharmaceutical Application: A review ,IJPRAS.ISSN2277-2236 vol.1,Issue2(2012),06-11.

[6] Y.S.Lee, S.S. Lim, K.H. Shin, Y.S. Kim, K. Ohuchi, S.H. Jung, Biol. Pharm. Bull, 29, (2006),1028-1031.

[7] Reinitzer, Monatsh 9,(1888) 421.

[8] E. Hertz, B. Lavorel and O.Faucher, Optical imagine by molecular gas, Nature photon; 5 (2011) PP.783.

[9] Macros . M, Omenat. A, ,Serrano. J.L and Ezcurra. A, Adv. Matter, 4 (1992), 285.

[10] Hird. M, Toyne. K.J,Gray G.W. , Day S.E. Liq. Cryst.14 (1993), PP. 741.

[11] C.T. Imrie , Liq. Crystal dimers. struct. Bond 95 (1999) PP. 149-192.

[12] Gray G.W. and Jones B., Mesomorphism and chemical constitution part-3, The effect of halogen substitution on the 4-Alkoxy benzoic acids, Journal of chemical society (1954) , PP, 25562562.

[13] P.J. Collings and M. Hird (1997), Introduction of Liquid crystals chemistry and Physics, Taylor and Francis Ltd. U.K.1998.

[14] Imrie C.T and Luckhrust G.R, “ Liquid Dimers and Oligomers in handbook of Liquid Crystal, law molecular liquid crystals; Vol. 2B, Demus D., Goodby J.W., Gray. G.W., Spiess H. and Vill V. eds, Willey-VCH Weinhe (1998), PP-801-833.

[15] Doshi et al (i) Suthar D.M. and Doshi A.V., Mol. Cryst. Liq. Cryst. Vol. 575(2013) PP.7683.(ii) Chauhan H.N. and Doshi A.V., Mol.Cryst. Liq. Cryst. Vol. 570(2013) PP. 92-10. (iii) Chaudhari R.P, Chauhan M.L., and Doshi A.V., Vol. 575,(2013) PP. 88- 95.

[16] Patel B.H. and Doshi A.V. "Mesomorphism and Molecular : Novel Homologous Series 4-(4'-n-alkoxy cinnamoyloxy)-4"'-methoxy Benzyl Benzoate" Mol. Cryst. Liq. Cryst. , Vol -607 (2015) PP.78-86.

[17] Patel R.B., Patel V.R., Doshi A.V., Mol. Cryst. Liq. Cryst., 552: (2012) PP.3-9.

[18] Yelamaggad, C. V., Achalkumar, A.S., Bonde, N.L., Prajapati, A.K., Chem. Mater. 18, (2006) 1076.

[19] Nelida Gimeno., M. Blanca Ros., RSC Adv., 4: (2014) 19694-19702. 
[20] Patel R.B., Chauhan M.L., Doshi A.V., Der Pharma Chemica, 2(6)(2010) 157-164.

[21] Patel R.B. and Doshi A.V., Der Pharma Chemica,3(2) (2011) PP 147-155.

[22] Dave J.S and Vora R.A(1970). In: J.F. Johnson and R.S.Porter, (eds), (Liquid crystals And ordered fluids, Plenum Press: New York, P. 477.

[23] Y.Quin, H.J.Zhang, H.Zhang, C.Xu, J.Zhao, and H.L.Zhu, "Synthesis, molecular modelling, and biological evaluation of cinnamic acid metronidazole ester derivatives as novel anticancer agents”, Bioorganic and Medicinal Chemistry, vol. 18, no. 14, PP (2010) 4991-4996.

[24] Vinay S. Sharma., R.B. Patel, Manuscript of the research paper entitled, "Molecular Structure and Mesomorphism: Effect of Tail/Lateral Group" submitted for publication in Mol. Cryst. Liq. Cryst. Journal with its reference no. LCMH No. 326 date $28^{\text {th }}$ April 2015.

[25] Vinay S. Sharma., R.B. Patel, Manuscript of the research paper entitled, "Molecular Flexibility Dependence Mesomorphism" submitted for publication in Mol. Cryst. Liq. Cryst. Journal with its reference no. LCMH No. 337 date $25^{\text {th }}$ July 2015. 